GU J Sci, Part C, 7(1): 49-62 (2019)

Gazi Üniversitesi
Fen Bilimleri Dergisi
PART C: TASARIM VE TEKNOLOJI
http://dergipark.gov.tr/gujsc

\title{
Nötr Kenetlemeli Eviriciler için Çok Giriş - Çok Çıkışı DA-DA Çevirici Tasarımı ve Kontrolü
}

\author{
Naki GÜLER ${ }^{1, *}$ Erdal IRMAK ${ }^{2}$ \\ ${ }^{I}$ Gazi Üniversitesi, Teknik Bilimler Meslek Yüksekokulu, Elektrik ve Enerji Bölümü, 06374, Yenimahalle/ANKARA \\ ${ }^{2}$ Gazi Üniversitesi, Teknoloji Fakültesi, Elektrik-Elektronik Mühendisliği Bölümü, 06500, Yenimahalle/ANKARA
}

Öz

Makale Bilgisi

Başvuru: $29 / 11 / 2018$

Düzeltme: $12 / 12 / 2018$

Kabul: $21 / 12 / 2018$

\section{Anahtar Kelimeler \\ Cok Giriș - Çok Çıkıșlı $D A-D A$ Çevirici \\ Nötr Kenetlemeli Evirici \\ Gerilim kontrolü}

Keywords

Multi Input-Multi Output DC-DC Converter Neutral Point Clamped Inverter

Voltage Control
Bu çalışmada, Nötr Kenetlemeli Eviricilerin (NKE) hem çok girişli yapıya getirilmesi hem de gerilim dengesizliğinin giderilmesi için çok-giriş çok-çıkışlı bir DA-DA çevirici topolojisi sunulmuştur. Çok kaynaklı çalışma, önerilen çevirici modelinin çok girişli özelliği ile sağlanmıştır. Nötr kenetlemeli eviricilerde bozunumların artmasına sebep olan dengesiz kondansatör gerilimleri, bu topolojinin çok çıkıșlı özelliğiyle DA tarafta dengelenmiștir. Şebeke etkileşimli eviricinin kondansatör gerilimlerinin dengelenmesi ve güç akışını kontrol etmek için PI denetleyiciler kullanılmıştır. Önerilen topolojinin teorik altyapısını ve performansını doğrulamak için Matlab/Simulink platformunda benzetim çalışmaları gerçekleştirilmiştir. Benzetim sonuçları, iki giriş kaynağında üretilen enerjinin, NKE ve önerilen çevirici modeli aracılığıyla başarılı bir șekilde şebekeye aktarıldığını göstermiștir. NKE kondansatör gerilimlerinin eşitliğini bozsa da, gerilim dengelenmesi kontrolörler ve önerilen dönüştürücü modeli tarafından sağlanmıştır. Dengeli ve dengesiz koşullar altında elde edilen sonuçlar, önerilen sistemin bozunumları önemli ölçüde azalttığını göstermiştir.

\section{Design and Control of Multi - Input Multi - Output DC-DC Converter for Neutral Point Clamped Inverters}

\begin{abstract}
In this study, multi-input multi-output DC/DC converter topology is presented for both multisource operation and voltage unbalancing of Neutral Point Clamped (NPC) inverters. Multisource operation is provided with multi-input feature of proposed converter model. The unbalanced capacitor voltages in NPC inverter leading to increase the harmonics are compensated on the DC side by the multi-output feature of this topology. PI controllers are utilized to control the capacitor voltages and power flow of grid connected inverter. Simulation studies are performed in Matlab/Simulink platform to verify the theoretical background and performance of the proposed topology. Simulation results show that, produced power from two input sources is successfully transferred to grid through the proposed converter structure and NPC inverter. Even if NPC inverter disturbs the equality of capacitor voltages, the voltage balance is maintained by the controllers and proposed converter model. The results that are obtained under balanced and unbalanced conditions show that, the proposed system considerably decreases the harmonics.
\end{abstract}

\section{GİRIŞ (INTRODUCTION)}

Yenilenebilir enerji kaynaklarının kullanılması ile farklı türde üreteçlerin birlikte çalışabilirliği önem kazanmıştır. Aşağıda verilen güncel literatür özetinden görüldüğü üzere, birden çok kaynağın birlikte çalışabilmesi için çok girişli güç çevirici tasarımları yapılmaktadır. Bu kaynaklarda üretilen enerjinin şebekeye transferinde kullanılan eviricilerin tasarımı ve kontrolü son yıllarda çalışılan konular arasında yer almaktadır. Bunların yanı sıra, enerji kalitesi kavramı da tüm sistemler için önem kazanmıştır[1]. Enerji kalitesinin klasik topolojilere göre iyi olması çok seviyeli eviricileri ön plana çıkarmıştır. Nötr kenetlemeli eviricilerin, klasik evirici yapılarına göre avantajları aşağıdaki gibi sıralanabilir:

- Düşük anahtarlama frekanslarında dahi düşük bozunuma sahip güç akışı sağlanabilmesi. 
- Anahtarlar üzerindeki gerilim stresinin az olmas1.

- Anahtarlama kayıplarının az olması.

- Düşük boyutlu filtreler kullanması.

Nötr kenetlemeli eviriciler, diğer çok seviyeli evirici topolojilerine göre (kaskat H-köprü ve uçan kondansatörlü) yüksek gerilim seviyesinde çalışabilme ve özel devre elemanına ihtiyaç duymama gibi avantajlara sahiptir. Yaygın olarak kullanılan bu topoloji üzerine literatürde geliştirme çalışmaları yapılarak model üzerindeki problemlerin giderilmesi hedeflenmiştir. Diyot kenetlemeli evirici modelinde, faz kollarındaki diyotlardan geçen kontrolsüz akımlar ve her anahtar üzerinden geçen tam güç akımları kayıpları artırmaktadır. Diyotların kaldırılması ve ana koldaki anahtar sayısının azaltılması için T-NKE (T baralı Nötr Kenetlemeli Evirici) topolojisi geliştirilmiştir[2]. T-NKE modelinde ise anahtarların blok diyotlarından geçen yüksek akımlar özel yapılara ihtiyaç duyulmasına sebep olmuştur. Bu olumsuz durumun giderilmesi için $\mathrm{T}$ barasındaki anahtarlama elemanlarının blok diyotları kaldırılarak GT-NKE (Gelişmiş T tipi NKE) topolojisi oluşturulmuştur[3]. NKE yapısı üzerinde iyileştirme çalışmaları ile birçok olumsuz durum giderilse de tek kaynaklı çalışması ve giriş kondansatörlerinde meydana gelen gerilim dengesizliği problemi hala birer dezavantaj oluşturmaktadır.

Özellikle yüksek güçlü uygulamalar için birden çok eviricinin paralel bağlanması ile çok kaynaklı çalışabilirlik sağlanırken[4], orta ve düşük güçlü uygulamalarda, giriş kaynakları çeviriciler aracıllı̆̆yla ortak bir DA baraya bağlanmaktadır. Böylece, hem kaynaklar arasındaki güç paylaşımı hem de DA bara gerilimlerinin kontrolü bu çeviriciler ile sağlanmaktadır[5-7]. Ayrı çeviriciler kullanılan bu sistemlerin yanı sıra, birden çok girişe sahip çeviriciler de son yıllarda yaygın çalışılan konular arasında yer almaktadır[8, 9]. Bu topolojilerde klasik yapılar üzerinde düzenlemeler yapılarak bağımsız giriş kaynaklarından güç akışı sağlanmaktadır. Çok girişli yapıların yanı sıra, çok çıkışlı çevirici topolojileri de sabit çıkış gerilimi veya farklı gerilim seviyesine sahip yüklerin beslenmesinde kullanılmaktadır[10-13]. Çok giriş - çok çıkışlı DADA çeviriciler ise her iki özelliği de birlikte barındırır. Bu yapılarda, güç akışının ve çıkış gerilimlerinin birbirinden bağımsız olarak yönetilmesi temel unsurlardır. Çok giriş - çok çıkışlı topolojilerde tek bobin kullanımı ile maliyet ve boyut azaltılabilirken, bu durum çıkış tarafındaki gerilim kazancını sınırlamaktadır[14,15]. Bu nedenle, yüksek gerilim kazancı istenilen uygulamalarda her kaynak için ayrı bir bobin kullanılmaktadır. Ayrıca, tek bobin kullanımı düşük güçlü uygulamalarda sorun oluşturmazken, orta ve yüksek güçlü yapılarda giriş kaynağından dengesiz akımlar çekilmesine neden olmaktadır. Bağımsız bobin kullanımı bu açılardan avantaj sağlamaktadır. Kontrol işlemleri açısından karşılaştırıldığında da güç katmanlarını ayrı ayrı yönetmek, karmaşık kontrol yapısı ihtiyacını ortadan kaldırmaktadır[16]. Üreteçlerin entegrasyonu hakkında sunulan literatür özeti doğrultusunda, çok girişli bir DA-DA yapı ile enerji kaynaklarında üretilen gücün sabit gerilime sahip ortak bir DA barada birleştirilebileceği söylenebilir.

Sabit bir DA bara gerilimi olmasına rağmen, NKE çıkışındaki dengesiz yüklenmeden kaynaklanan nötr akımı, giriş kondansatörleri arasındaki gerilim dengesini bozmaktadır. Bu durum alternanslar arasında gerilim farkı yaratmakta ve buna bağlı olarak bozunumları artırmaktadır[17]. Ayrıca, gerilim dengesizliğinden kaynaklı pozitif ya da negatif taraftaki kondansatör geriliminin artması, anahtarlar üzerindeki gerilim stresini de artırmaktadır. Bu olumsuz etkilerin giderilmesi son yılların yaygın çalışılan konuları arasında yer almıştır. Yapılan çalışmalarda, herhangi bir güç anahtarına ihtiyaç duymaksızın sadece güç kontrol algoritmasına kondansatör davranışlarının eklenmesi ile gerilim dengesi sağlanmıştır[18-21]. [10]'de ise diğer çalışmalardan farklı olarak DA girişte gerilim dengesizliğinin giderilmesi incelenmiştir. Bunun için, tek giriş - iki çıkışlı bir yükselten çevirici giriş kondansatörlerine bağlanarak her katmanın çıkışı bağımsız olarak kontrol edilmiştir. Fakat bu modelin tek girişe sahip olması sebebiyle NKE çok kaynaklı çalışamamaktadır. Aynı zamanda [10]'daki modelde, 4 adet ek anahtar kullanılması, hem kontrol işlemlerini zorlaştırmış hem de toplam sistem maliyetini artırmıştır.

Bu çalışmada önerilen model ile nötr kenetlemeli evirici hem çok girişli hale getirilmiş hem de gerilim dengelenmesi DA tarafta sağlanmıştır. Birbirinden bağımsız giriş kaynaklarında üretilen gerilimler iki giriş̧ - iki çıkışa sahip çevirici modeli ile yükseltilerek çıkışlara aktarılmıştır. Bu çıkışlar, NKE girişindeki kondansatörlere bağlanarak kaynaklardan eviriciye güç akışı sağlanmıştır. Böylece, paralel evirici topolojilerine göre daha basit bir güç yapısı ile eviricinin çok kaynaklı çalışabilirliği sağlanmıştır. Önerilen modelin en önemli unsuru ise bağımsız kontrol edilebilen çıkışlara sahip olmasıdır. Böylece, nötr 
kenetlemeli evirici girişindeki gerilim dengesizliği problemi DA tarafta giderilmiştir. Bu durum, gerilim dengelenmesi için kullanılan karmaşık kontrol yapısı ihtiyacını ortadan kaldırılmıştır.

\section{SISTEM TASARIMI (DESIGN OF THE SYSTEM)}

Önerilen sistem, üç fazlı üç seviyeli nötr kenetlemeli eviricinin çok girişli çalışmaya uygun hale getirilmesi ve nötr noktası gerilim dengesizliğinin DA tarafta giderilmesi için tasarlanmıştır. Bu amaçla, çok giriş çok çıkışı DA-DA çevirici modeli oluşturulmuştur. İki girişe sahip sistem modeli Şekil 1'de verilmiştir. Giriş olarak kullanılan ( $V_{i n 1}$ ve $\left.V_{i n 2}\right)$ kaynakların farklı gerilim seviyesinde olma durumları göz önünde bulundurularak iki ayrı yükselten çevirici katmanı kullanılmıştır. Aynı zamanda, nötr noktası gerilim dengesinin sağlanması da bağımsız çalışan bu iki katman sayesinde gerçekleştirilmiştir. Çıkışların bağımsız olarak kontrol edilebilmesi için her katmanda ayrı anahtar ve bobin kullanılmıştır. Katmanların çıkışındaki kondansatör gerilimleri ile referans değer arasındaki farklar ayrı PI $\left(P I_{D C(1)}\right.$ ve $\left.P I_{D C(2)}\right)$ denetleyicilere girilmiştir. Anahtarlama sinyallerinin doluluk oranları $(d(1)$ ve $d(2))$ PI kontrolörler tarafından üretilerek bir taşıyıcı sinyal (üçgen dalga) ile karşılaştırılmıştır. Böylece, gerilim kontrolü için gerekli anahtarlama sinyalleri üretilmiştir. Bağımsız olarak güç ve gerilim kontrolü yapılan çevirici çıkışları, NKE girişindeki kondansatörlere bağlanarak çevirici - evirici etkileşimi sağlanmıştır.

DA tarafta üretilen gücün şebekeye aktarılması için kullanılan GT-NKE modeli Şekil 1'de görülmektedir. 3 seviyeli NKE topolojileri bir faz sinyalini üretmek için 4 adet anahtar kullanmaktadır. Bir faz için oluşturulan kol, faz sayısına göre çoğaltılarak 3 fazlı yapı oluşturulmaktadır. GT-NKE tip evirici, her kolundaki nötr noktasına $(M)$ bağlı iki anahtar $\left(T_{3}\right.$ ve $\left.T_{4}\right)$ sayesinde 3 'üncü bir seviye oluşturmaktadır.

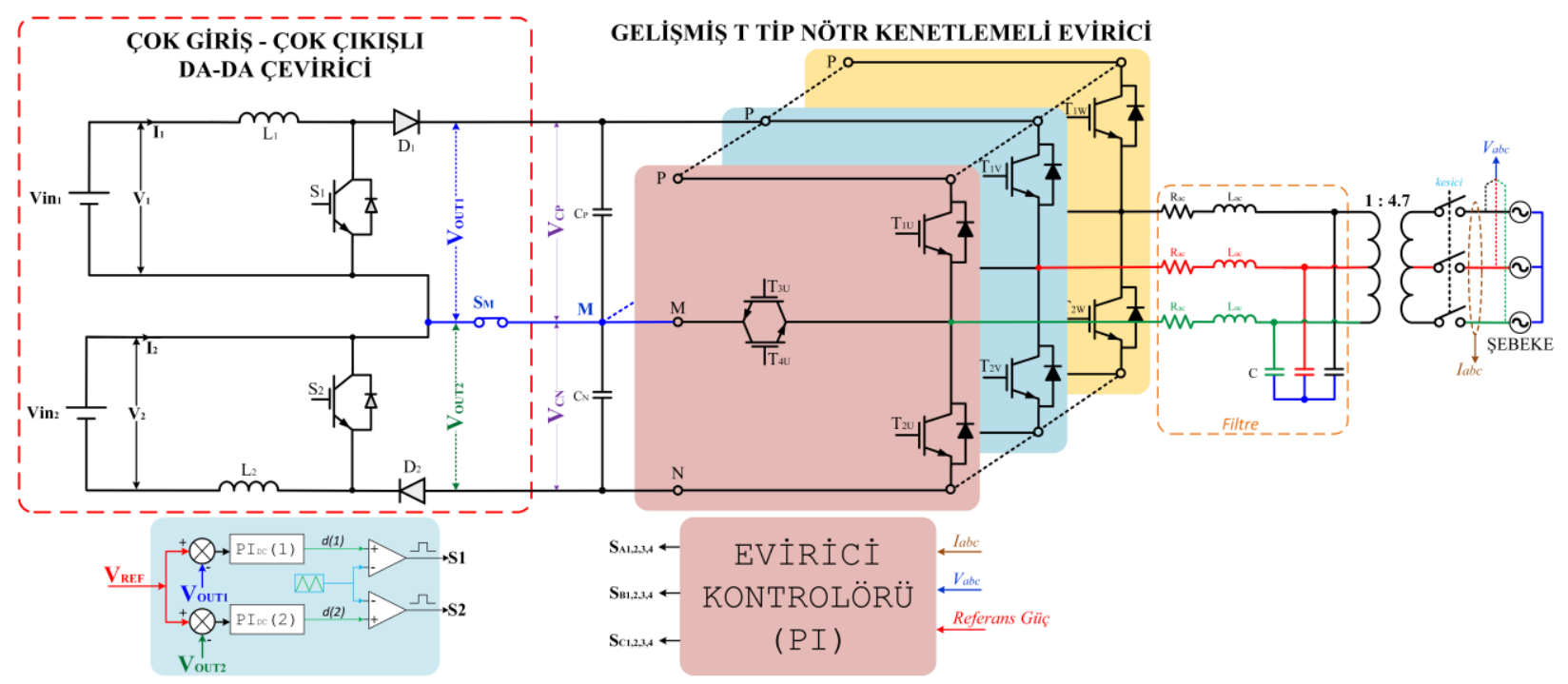

Şekil 1. Sistemin blok diyagramı

Şekil 2(a)'da verilen anahtarlama sinyallerinden görüldüğü üzere, bir alternansın oluşturulması için aynı anda iki anahtar iletimde olmaktadır. Tüm anahtarlar, pozitif ve negatif bara arasında anahtarlama yapmak yerine, pozitif $(P)$ - nötr noktası $(M)$ veya negatif $(N)$ - nötr noktası arasında anahtarlama yapmaktadır. Böylece, Şekil 2(b)'de verilen Seviye - 2'nin oluşması sağlanmaktadır. Üçüncü bir seviyenin oluşmasını sağlayan bu durumun diğer avantajı ise, anahtarlar üzerindeki gerilim stresini klasik evirici topolojisine göre yarıya düşürmesidir.

Nötr kenetlemeli eviricilerin ideal çalışması giriş kondansatörleri üzerindeki gerilimlerin ( $V_{C P}$ ve $\left.V_{C N}\right)$ eşit olduğu durumda gerçekleşmektedir. Anahtarlama sinyalleri de bu dengeli durum için üretilmektedir. Ancak, dengesiz yüklenmeden ve filtrelerden kaynaklı sıfır bileşen akımı oluştuğunda, giriş̧ kondansatörlerindeki gerilim eşitliği bozulmaktadır. Bu durumun incelenmesi için örnek bir sonuç Şekil 3'te verilmiştir. Kondansatör gerilimlerinin eşit olmaması, Seviye-2'nin gerilim değerini değiştirmekte ve simetrik olmayan 4'üncü bir seviye oluşturmaktadır. Bu durum, nötr noktası gerilim dengesizliği olarak ifade edilmektedir. 

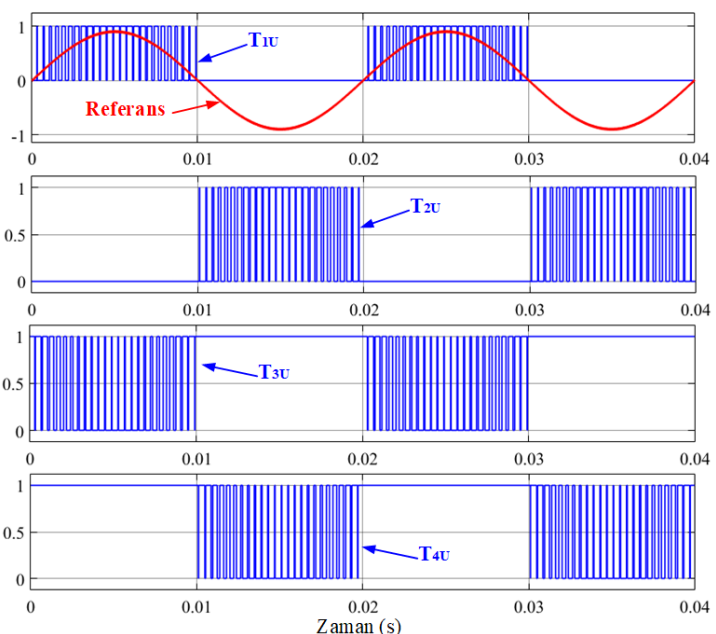

(a)

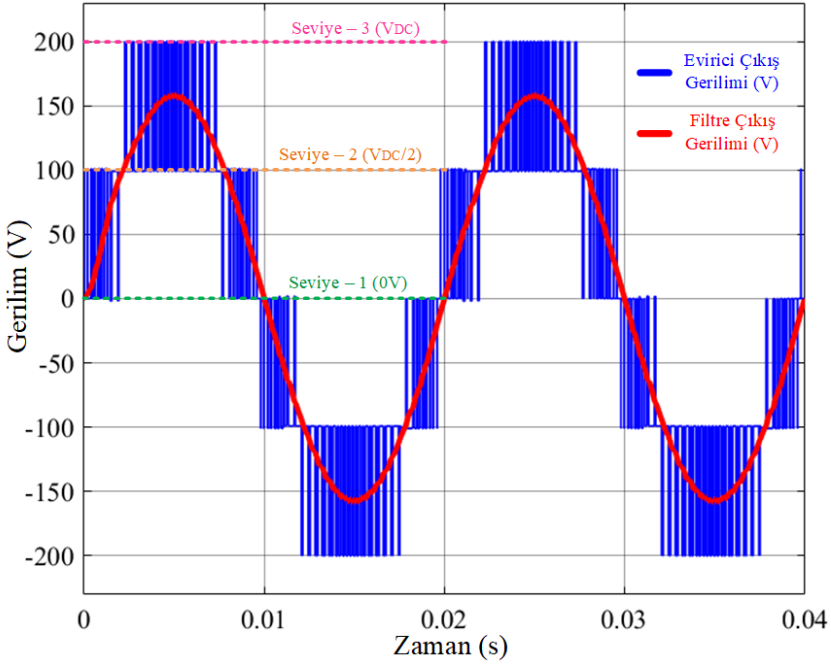

(b)

Şekil 2. a: Anahtarlama sinyalleri, b: Dengeli nötr barası durumunda evirici çıkış gerilimi

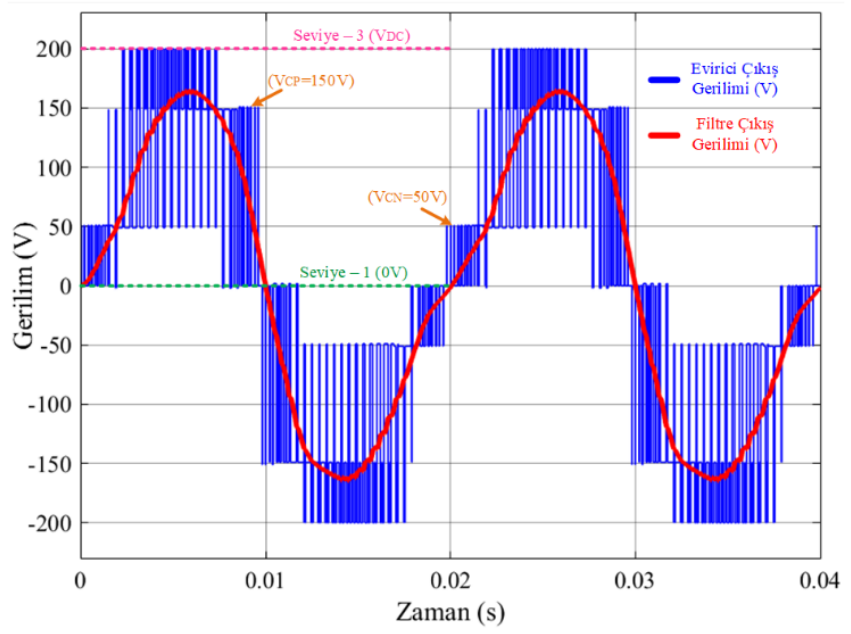

Şekil 3. Dengesiz nötr noktası durumunda evirici çıkış gerilimi

Şekil 3'te görüldüğü üzere, simetrik olmayan artışlar nedeni ile evirici gerilimi üzerinde bozucu etkiler oluşmakta ve şebekeye yüksek bozunuma sahip güç aktarılmasına sebep olmaktadır. Bu nedenle, kondansatör geriliminin dengelenmesi NKE’ler için önemli bir unsurdur.Kondansatör gerilimlerinin eşitlenmesinin yanı sıra, uygun kapasitede kondansatör seçimi de NKE'ler için önemlidir. Çünkü, bu kondansatörler hem nötr noktasını oluşturmak hem de giriş gerilimini filtre etmek için kullanılmaktadır. DA bara gerilimindeki salınım miktarını kabul edilebilir sınırlar içerisinde tutmak için gerekli kapasite Denklem 1 ile hesaplanmaktadır[22,23]. DA baradaki salınım miktarı kondansatörlerden çekilen güç değeri ile doğru orantılı olarak artmaktadır. Stabil bir DA bara gerilimi elde etmek için çok yüksek kapasiteli kondansatörler kullanılabilir. Fakat bu durum filtre boyutunu ve maliyeti artırmaktadır. Temel olarak, salınım miktarı bozunumları önemli oranda etkilemiyorsa geçerli kapasite uygulanabilirlik açısından yeterli kabul edilebilir. Bu çalışmada kabul edilebilir salınım oranı (\%salınım) \%20 olarak seçilmiştir. Şebekeye senkron olarak $50 \mathrm{~Hz}$ frekansta çalışan 3 fazlı evirici, bir periyot boyunca 6 alternans oluşturmaktadır. Bu nedenle salınım frekansı, şebeke frekansının 6 katıdır. Verilen açıklamalar doğrultusunda, 200V toplam DA bara gerilimi ve $\% 20$ salınım oranı için toplam kapasite Denklem 1'den $2083 \mu \mathrm{F}$ olarak hesaplanmıştır. Nötr kenetlemeli eviricilerde pozitif ve negatif olmak üzere iki giriş noktası bulunduğundan her girişe toplam kapasitenin yarısı değerinde kondansatörler bağlanmaktadır[22,23]. Bu nedenle pozitif ve negatif katmana $1000 \mu \mathrm{F}$ değerinde kondansatörler bağlanmıştır. 


$$
C_{D A}=\frac{P}{\left(V_{C P}+V_{C N}\right)^{2}(\% \text { salınım }) 6 f_{\S}}
$$

Burada;

$C_{D A}$ : DA bara kondansatör kapasitesi

$P$ : Evirici nominal gücü $(2.5 \mathrm{~kW})$

$V_{C P}$ : Pozitif baraya bağlı kondansatör gerilimi $(100 \mathrm{~V})$

$V_{C N}$ : Negatif baraya bağlı kondansatör gerilimi $(100 \mathrm{~V})$

$f_{S ̧}:$ Şebeke frekansı $(50 \mathrm{~Hz})$

DA bara kondansatörlerinin belirlenmesinin yanı sıra, çıkış filtreleri de enerji kalitesi bakımından büyük öneme sahiptir. Evirici çıkışında elde edilen çok seviyeli gerilim sinyallerinin sinüzoidal biçime getirilmesi için LC filtre kullanılmıştır. LC filtre parametreleri [24]'te detayları verildiği gibi, sistem tasarımına bağlı olarak hesaplanmaktadır. Filtre endüktansının minimum değeri Denklem 2 ile hesaplanabilir. Evirici çıkışında transformatör olduğundan filtre gerilimi Denklem 3 kullanılarak hesaplanmıştır.

$$
\begin{aligned}
L_{a c} & \geq \frac{5 \sqrt{2}\left(V_{C P}+V_{C N}\right) T_{s w} V_{a c}}{2 P} \\
V_{a c} & =380 / 4.7=80.85 \mathrm{~V}
\end{aligned}
$$

Burada;

$L_{a c}:$ Filtre endüktans1

$T_{S W}$ : Anahtarlama frekansının periyot süresi $(400 \mu \mathrm{s})$

$V_{a c}$ : Evirici çıkış gerilimi (Transformatör öncesi)

Denklem 2 kullanılarak minimum filtre endüktansı $9.15 \mathrm{mH}$ bulunmuştur. Bu değerden büyük bir filtre seçilmesi enerji kalitesi açısından önemlidir. Fakat çıkışa seri bağlı bu bobin üzerindeki gerilim düşümü filtre boyutuna bağlı olarak artmaktadır. Bu nedenle maksimum filtre endüktansı Denklem 4 ile hesaplanmaktadır[24].

$$
L_{a c} \leq \frac{\sqrt{\left(V_{C P}+V_{C N}\right)-4\left(V_{a c}\right)^{2}}}{2 \sqrt{2} I_{a c} \omega_{\S}}
$$

Burada;

$I_{a c}$ : Evirici çıkış akımı (9A)

$\omega_{\text {ş }}$ : Şebeke açısal frekansı $(314 \mathrm{rad} / \mathrm{s})$

Gerilim düşümü ve enerji kalitesi göz önünde bulundurularak akım değeri nominal gücün yarısı için 9A olarak hesaplanmıştır. Denklem 2 ve Denklem 4'ten elde edilen değerler göz önünde bulundurularak filtre endüktans $15 \mathrm{mH}$ olarak seçilmiştir. Genellikle filtre kondansatörü hesaplanırken reaktif güç, nominal güç değerinin \%5'ini aşmayacak şekilde seçilmektedir[24]. Kondansatör kapasitesinin maksimum değeri Denklem 5 ile hesaplanabilir.

$$
C \leq \frac{5}{100} \times \frac{P}{6 \pi f_{\S} V_{a c}{ }^{2}}
$$

Burada;

$C$ : Filtre kondansatörünün kapasitesi

Denklem 5 kullanılarak maksimum kapasite $20 u F$ olarak hesaplanmıştır. Filtre kondansatörü güç katsayısının azalmasına sebep olduğundan belirlenen değer simülasyon çalışmalarında test edilerek, $10 u F$ filtre kapasitesinin enerji kalitesi ve reaktif güç üzerinde meydana gelen salınımlar açısından yeterli olduğu görülmüştür. 


\section{1. Şebeke Etkileşimi Eviricinin Güç Kontrolü (Power Control of Grid Connected Inverter)}

Enterkonnekte şebekelere bağlı tüm üreteçlerde olduğu gibi eviricilerde de paralel bağlantı öncesi ve sonrası durumların kontrol edilmesi gerekmektedir. Herhangi bir üretecin şebekeye güvenli bir biçimde bağlanması için, gerilim genliğinin, faz açısının ve frekansının şebeke ile örtüşmesi gerekmektedir. $\mathrm{Bu}$ nedenle, kontrol işlemleri bağlantı öncesi ve sonrası için ayrı ayrı incelenmiştir. Şebeke faz açısı ve frekansının belirlenmesinde faz kilitlemeli çevrim $(F K C ̧)$ en yaygın kullanılan yöntemdir. FKÇ, girişine uygulanan sinyalin açısal hız $(\omega t)$ bilgisini üretmektedir. Açısal hız sinüs fonksiyonuna tabi tutularak evirici kontrolü için gerekli referans sinyaller üretilmektedir. Bu sayede, evirici hem şebeke faz açısında hem de şebeke frekansında çalışmaktadır.

Paralel bağlantı öncesi için diğer şart olan gerilim genliğinin eşitlenmesi için şebeke gerilimi $\left(V_{S ̧(a b c)}\right)$ ölçülerek Şekil 4'teki gibi evirici çıkış gerilimi $\left(V_{a b c}\right)$ ile farkı hesaplanmıştır. Etkin değer fonksiyonunun hesaplama süresi daha uzun zaman aldığından, Park dönüşümleri sayesinde gerilimlerin tepe değerleri $\left(V_{s(d)}\right.$ ve $\left.V_{(d)}\right)$ elde edilmiştir. Fark alma işlemi sonucunda elde edilen hata sinyali, şebeke bağlantısı öncesinde evirici çıkış gerilimini kontrol eden $P I(1)$ denetleyicisine girilmiştir. PI denetleyici hata sinyaline göre modülasyon indeksini $(m a(1))$ değiştirerek evirici çıkış geriliminin şebeke gerilimine eşitlenmesini sağlamaktadır. Tablo 1'de verilen PI parametreleri, Ziegler-Nichols açık döngü yöntemi kullanılarak hesaplanmıştır.

Tablo 1. PI Parametreleri

\begin{tabular}{ccc}
\hline & $\boldsymbol{k}_{\boldsymbol{p}}$ & $\boldsymbol{k}_{\boldsymbol{i}}$ \\
\hline$P I(1)$ & 0.01 & 0.5 \\
$P I(2)$ & 1 & 100 \\
$P I_{D C}(1)$ ve $P I_{D C}(2)$ & 0.0008 & 0.6 \\
\hline
\end{tabular}

Gerilim ve faz açısının eşitlenmesinden sonra evirici-şebeke bağlantısı sağlanmaktadır. Bu süreçten itibaren Şekil 4'teki $m a(2)$ ve $a c ̧ ı$ bilgisi ile güç akışı kontrol edilmektedir. Şebekeden eviriciye doğru ters güç akışının engellenmesi ve kontrollerin doğru bir şekilde sağlanması için aktif ve reaktif bileşenlerin eş zamanlı olarak denetlenmesi gerekmektedir. Güç bileşenlerinin ayrı ayrı hesaplanması için evirici çıkış akımı $\left(I_{a b c}\right)$, Park dönüşümüne tabi tutularak $d$ ve $q$ bileşenleri elde edilmiştir. Bu iki değer evirici çıkışındaki gerilimin etkin değeri ile çarpılarak, aktif $\left(P_{h e s}\right)$ ve reaktif güç $\left(Q_{h e s}\right)$ bileşenleri hesaplanmıştır. Güç bileşenlerinin aynı PI denetleyici $(P I(2))$ ile kontrol edilmesi için bu değerler matris formuna getirilmiştir.

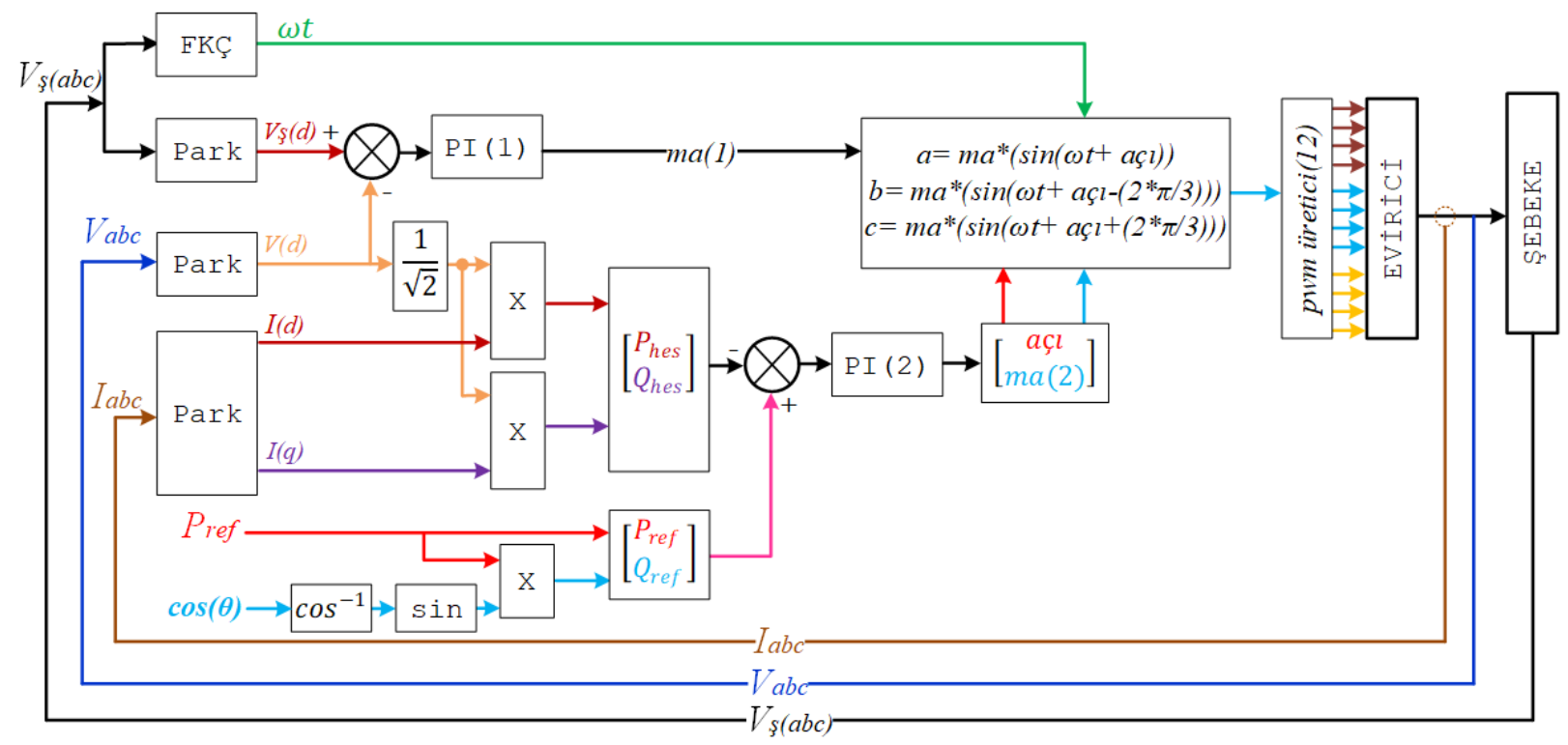

Şekil 4. Kontrol işlemlerinin blok gösterimi 
Referans aktif güç $\left(P_{r e f}\right)$ ve referans güç katsayısı $(\cos \theta)$ haricen girilmektedir. Eviricinin reaktif gücü hesaplandığından, $\cos \theta$ değeri kullanılarak referans reaktif güç $\left(Q_{r e f}\right)$ hesaplanmıştır. Hesaplanan ve ölçülen güç değerlerinin farkları alınarak hata sinyalleri elde edilmiştir. $P I(2)$ denetleyici bu hata değerlerine bağlı olarak, faz açısı ve modülasyon indeksi değerlerini oluşturmaktadır. Kontrol süreci sonunda elde edilen bu değerler referans sinüs sinyalleri üreten blokta sinüzoidal forma getirilmiştir. Üç faz için oluşturulan referans sinyallere bağlı olarak evirici anahtarlama sinyalleri üretilmiştir. Böylece, her iki güç bileşeni de referans değerlere göre kontrol edilmiştir. Kontrol sürecinden görüldüğü üzere, gerilim dengesizliği DA tarafta giderildiğinden güç akış yapısına herhangi bir ekleme yapılmamıştır.

\section{BENZETIM SONUÇLARI (SIMULATION RESULTS)}

Önerilen sistemin doğrulanması için Şekil 1'de verilen güç ve kontrol yapıları Matlab/Simulink ortamında modellenmiştir. Benzetim parametreleri Tablo 2'de sunulmuştur. Benzetim çalışmasında şebekeye güç akışının analizi için örnek bir senaryo oluşturulmuştur. Aynı model üzerinde, gerilim dengesizliği durumunun da incelenmesi için, güç yapısına Şekil 1'deki SM anahtarı eklenmiştir.

\section{Tablo 2. Benzetim Parametreleri}

\begin{tabular}{ll}
\hline Parametre & Değeri \\
\hline Kondansatör $\left(C_{P}\right.$ ve $\left.C_{N}\right)$ & $1000 \mu \mathrm{F}$ \\
Çevirici anahtarlama frekansı & $5 \mathrm{kHz}$ \\
Bobin $\left(L_{1}\right.$ ve $\left.L_{2}\right)$ & $1 \mathrm{mH}$ \\
Filtre Kondansatörü $(C)$ & $10 \mu \mathrm{F}$ \\
Bobin iç direnci $\left(R_{L}\right)$ & $0.2 \Omega$ \\
Filtre bobini $\left(L_{a c}\right)$ & $15 \mathrm{mH}$ \\
Evirici anahtarlama frekansı & $2.5 \mathrm{kHz}$ \\
Şebeke & $380 \mathrm{~V}-50 \mathrm{~Hz}$ \\
Örnekleme süresi $\left(T_{S}\right)$ & $20 \mu \mathrm{s}$ \\
PI(1) ve PI(2) örnekleme süresi & $100 \mu \mathrm{s}$ \\
$P_{D C(1)}$ ve PI $I_{D C(2)}$ örnekleme süresi & $200 \mu \mathrm{s}$ \\
\hline
\end{tabular}

Benzetim çalışmaları öncelikle gerilim dengesinin kontrol edilmediği durum $\left(S_{M}=0\right)$ için gerçekleştirilmiştir. Bu duruma ait sonuçlar Şekil 5-7'de sunulmuştur. Evirici kontrolünde belirtildiği üzere, şebeke bağlantısı gerçekleşmeden önce, eviricide üretilen gerilimin şebeke şartlarına getirilmesi için kontrol işlemleri yürütülmektedir. Şekil 5 'te verilen güç bileşenlerine ait sonuçlardan görüldüğü üzere, bağlantı anı öncesinde evirici yüksüz olduğundan sadece filtre üzerinde güç harcanmaktadır. Filtre sadece reaktif elamanlar barındırdığından güç katsayısı sürekli olarak değişmektedir. Şebeke bağlantısının gerçekleşmesi ile kontrol mekanizması güç akışını denetlemeye başlamaktadır. 1,5kW aktif güç ve 0.99 sabit güç katsayısı başlangıç koşulları ile evirici - şebeke arası bağlantı gerçekleşmiştir. Bu referans değerler ile çalışma sürecinde (başlangıç anı - 0.4s), güç akışı küçük salınımlar ile sağlanmaktadır.

Başlangıçtan sonra ise hem aktif güç hem de reaktif güç üzerindeki salınımlar artarak devam etmektedir. Aynı zaman diliminde, kondansatör gerilimleri $\left(V_{C P} v e V_{C N}\right)$ arasındaki farkın giderek arttığı Şekil 6'daki sonuçlardan görülmektedir. Bu esnada, çevirici katmanları arasındaki anahtar (SM) açık olduğundan, çevirici çıkış gerilimleri kondansatör gerilimlerinden farklı değerlerdedir. Her iki katmanı kontrol eden PI denetleyicilerin farklı giriş gerilimlerine rağmen, çevirici çıkışlarının ortalama değerini referansa (100V) eşitlediği görülmektedir. Böylece, DA bara gerilimi her zaman $200 \mathrm{~V}$ seviyesinde tutulmaktadır. Fakat kondansatörler arası gerilim dengesi kontrol edilmediğinden neredeyse tüm $\mathrm{DA}$ bara gerilimi $\mathrm{V}_{\mathrm{CN}}$ kondansatörüne aktarılmaktadır. 

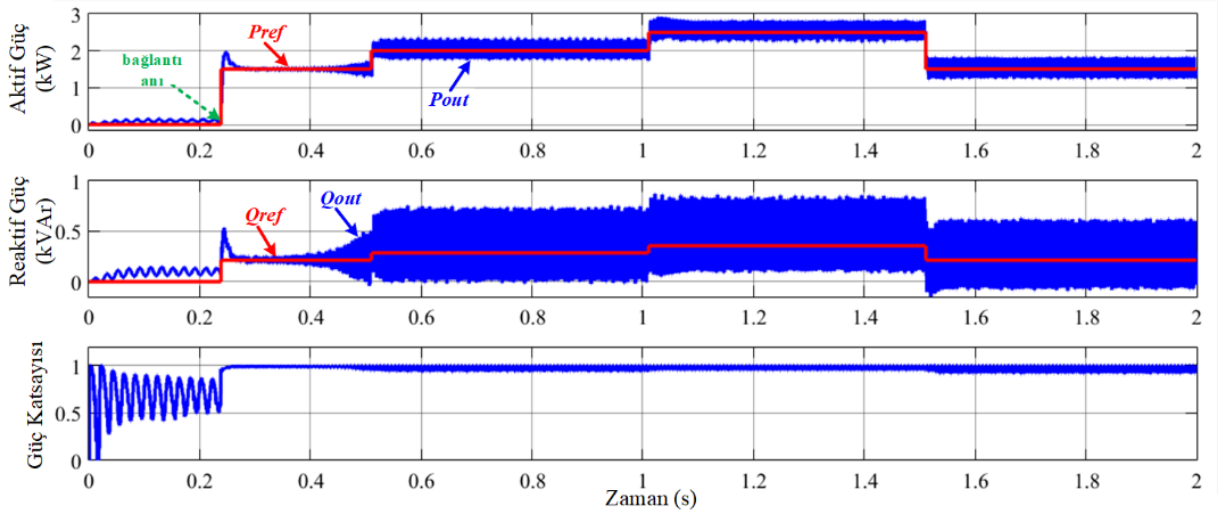

Şekil 5. Kontrolsüz nötr noktası durumundaki güç sonuçları
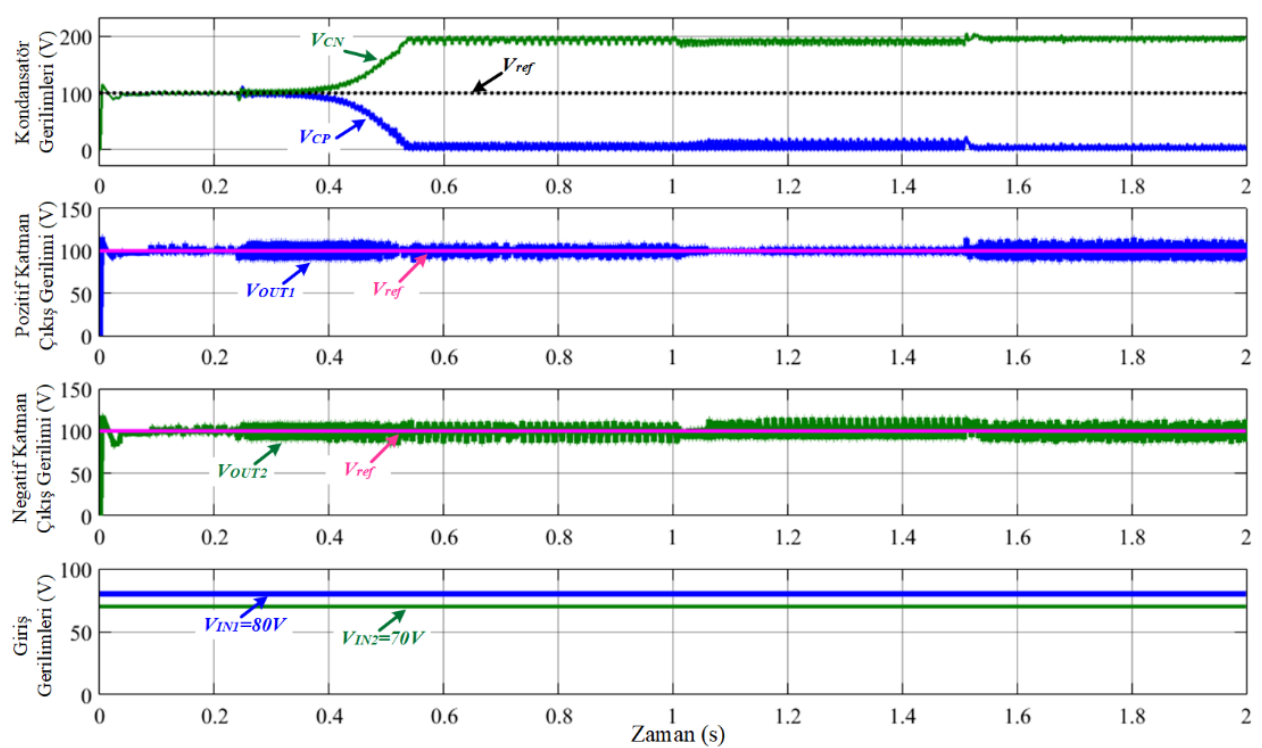

Şekil 6. Kontrolsüz nötr noktası durumundaki çevirici ve kondansatör gerilimleri
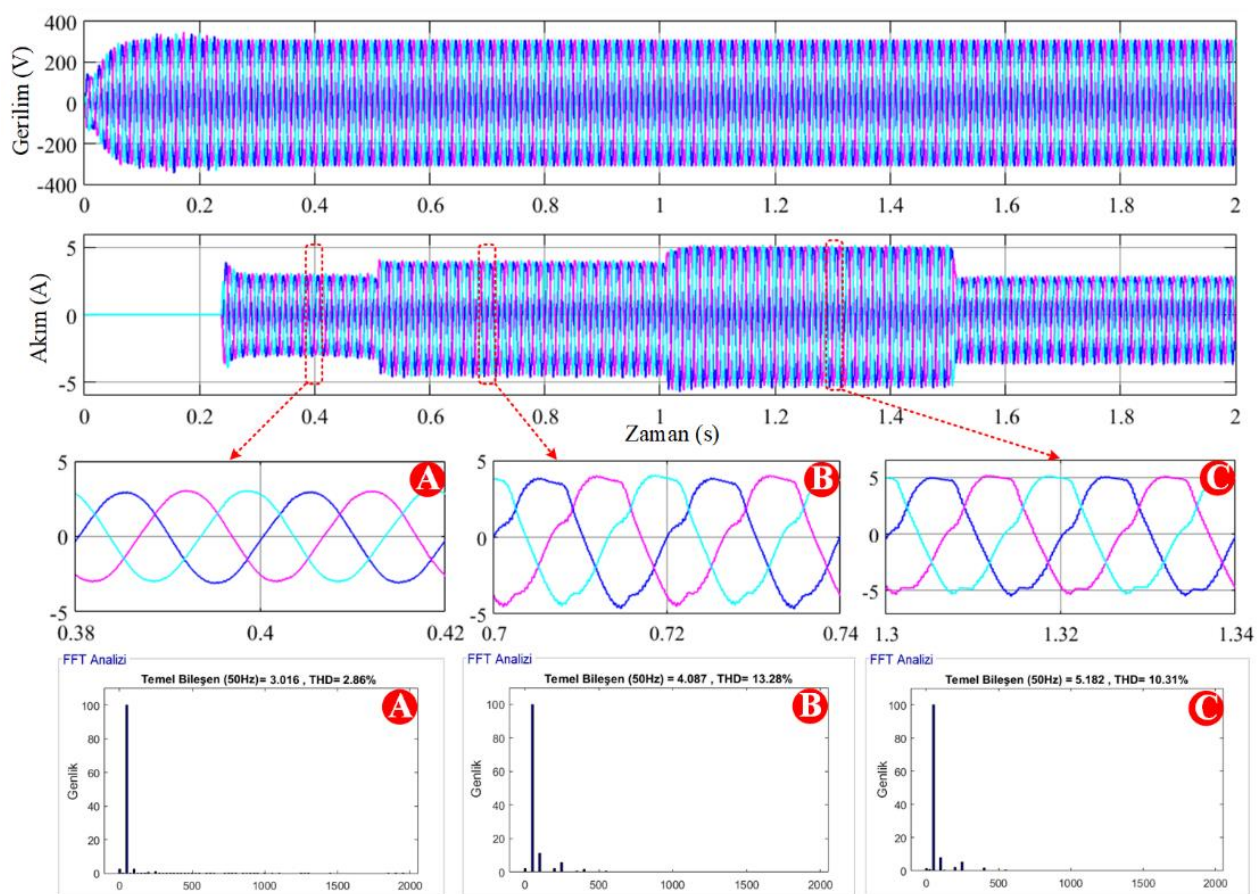

Şekil 7. Kontrolsüz nötr noktası durumundaki gerilim, akım ve bozunum sonuçları 
Güç akışının ve farklı yüklenme oranlarında gerilim dengesizliği durumlarının incelenmesi için referans güç değerleri basamak şeklinde değiştirilmiştir. $\mathrm{Bu}$ değişimlere rağmen $\mathrm{DA}$ bara geriliminin $200 \mathrm{~V}$ seviyesine sabitlendiği Şekil 6'dan görülmektedir. Fazlara ait gerilim ve akım sonuçları Şekil 7'de verilmiştir. Referans güç değerinin değiştirildiği anlarda eviriciden şebekeye aktarılan akım değerlerinin de değiştiği şekilden görülmektedir. Güç kademelerindeki akım sonuçlarının incelenmesi için detaylı grafikler $(A, B$ ve $C)$ aynı şekil üzerinde verilmiştir.

Şekil 7'deki A sürecine ait detaylı akım grafiğinden, sinyal üzerinde yüksek seviyede bozucu bir etkinin olmadığı söylenebilir. Bu süreçte gerilim dengesizliği olmadığından, toplam bozunum \%2.86'dır ve bu değer IEEE 1547 standardında belirtilen \%5 sinırının altındadır.

Güç akışının ve farklı yüklenme oranlarında gerilim dengesizliği durumlarının incelenmesi için referans güç değerleri basamak şeklinde değiştirilmiştir. $\mathrm{Bu}$ değişimlere rağmen $\mathrm{DA}$ bara geriliminin $200 \mathrm{~V}$ seviyesine sabitlendiği Şekil 6'dan görülmektedir. Fazlara ait gerilim ve akım sonuçları Şekil 7'de verilmiştir. Referans güç değerinin değiştirildiği anlarda eviriciden şebekeye aktarılan akım değerlerinin de değiştiği şekilden görülmektedir. Güç kademelerindeki akım sonuçlarının incelenmesi için detaylı grafikler (A, B ve C) aynı şekil üzerinde verilmiştir.

Şekil 7'deki A sürecine ait detaylı akım grafiğinden, sinyal üzerinde yüksek seviyede bozucu bir etkinin olmadığı söylenebilir. Bu süreçte gerilim dengesizliği olmadığından, toplam bozunum \%2.86'dır ve bu değer IEEE 1547 standardında belirtilen \%5 sınırının altındadır. Referans değer 2kW iken detaylı akım sonuçları B grafiğinde verilmiştir. Bu süreçte, kondansatörler arasındaki gerilim dengesizliği en yüksek seviyededir. Akım grafiğinden görüldüğü üzere, dalga formu oldukça bozuktur ve toplam bozunum $\% 13.28$ 'dir.

Referans değerin $2.5 \mathrm{~kW}$ olduğu durumun incelenmesi için verilen $\mathrm{C}$ sürecinde de akım dalga formunun oldukça yüksek bozunuma (\%10.31) sahip olduğu görülmektedir. Bu süreçte de gerilim dengesizliği maksimum seviyededir.

Yüksek bozunuma sahip akımlar sadece güç kalitesini değil güç akış kontrolünü de olumsuz etkilemektedir. Şekil 6'da verilen güç sonuçlarından görüldü̆g̈ü üzere, şebekeye transfer edilen güç, referans değeri yüksek bir salınım ile takip etmektedir.

Kontrolsüz durumda elde edilen kontrol süreci ve güç kalitesine ait sonuçların karşılaştırılması için aynı koşullar altında sadece nötr noktasındaki anahtar $(S M)$ kapatılarak benzetim çalışması tekrarlanmıştır. Elde edilen sonuçlar Şekil 8-10'da verilmiştir. Nötr noktasını çevirici çıkışlarının ortak noktası ile birleştiren anahtar kapalı olduğundan kondansatör gerilimleri ilgili çevirici çıkış katmanı gerilimlerine eşittir. Bu nedenle, Şekil 9'da sadece kondansatör gerilimleri verilmiştir. Bağlantı anı öncesindeki güç parametrelerinin kontrolsüz durumla benzer olduğu Şekil 8'deki sonuçlardan görülmektedir. Aynı süreçte kondansatör gerilimlerinin küçük bir salınım ile referans değere eşitlendiği Şekil 9'da görülmektedir. Bağlantı anının incelenmesi için evirici ve şebeke gerilimlerinin detaylı grafikleri Şekil 9'da verilmiştir. Her iki sinyalin faz açısı ve genliği eşitlendiğinde şebeke bağlantısı gerçekleşmekte ve güç kontrol süreci başlamaktadır.

Kontrolsüz durumda olduğu gibi bağlantı anından sonra referans aktif güç $1.5 \mathrm{~kW}$ ve referans güç katsayısı 0.99 'dur. PI denetleyici, güç değerlerini yaklaşık 0.05 s'de referanslara eşitlemiştir. Şekil 8 'de verilen sonuçlar, bu süreçten itibaren oluşturulan basamak değişimlerde de güç takibinin başarılı bir şekilde gerçekleştiğini göstermektedir. Aynı zamanda, reaktif güç kontrolünün de sağlandığı güç katsayısı sonuçlarından görülmektedir. Referans gücün, $2.5 \mathrm{~kW}$ 'tan $1.5 \mathrm{~kW}$ 'a düşürüldügüü son basamakta güç katsayısı kısa süre 0.96'ya düşmüştür. Bu sürenin hemen ardından, kontrolör güç katsayısını tekrar 0.99'a sabitlemiştir. Çalışmanın temel hedefleri, çok kaynaklı çalışabilirlik ve gerilim dengesizliğinin giderilmesi olduğundan güç akışı kontrolüne ait daha fazla detay tartışılmamıştır. 

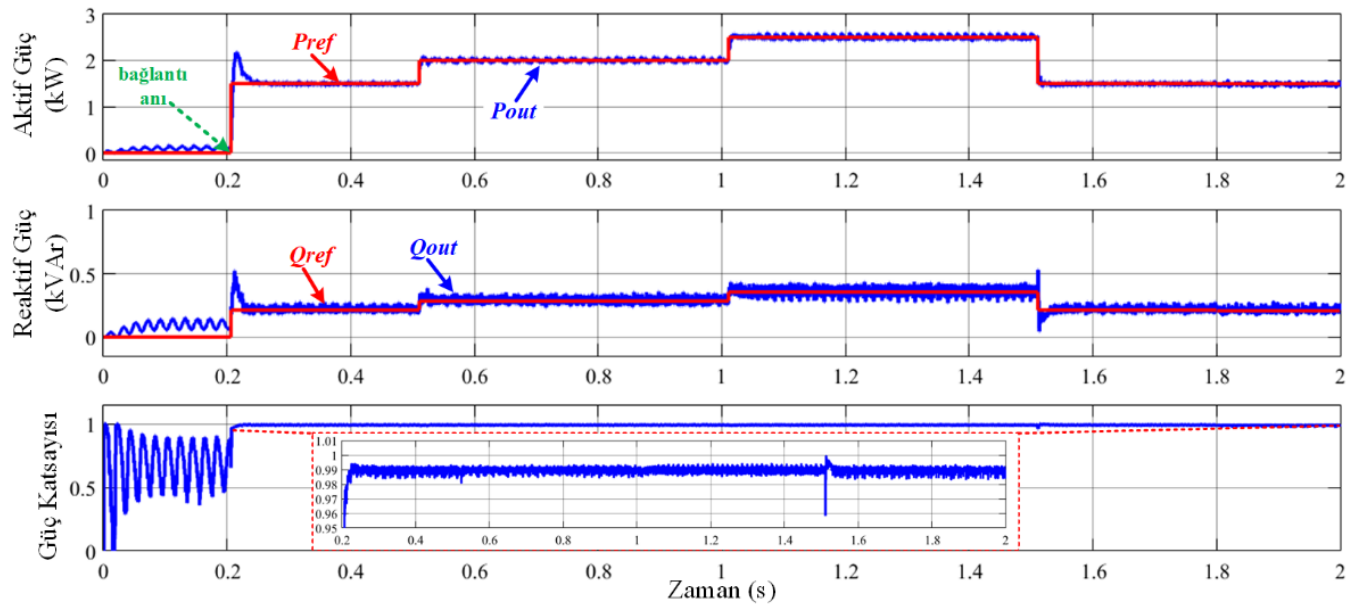

Şekil 8. Nötr noktasının kontrollü olduğu duruma ait güç sonuçları
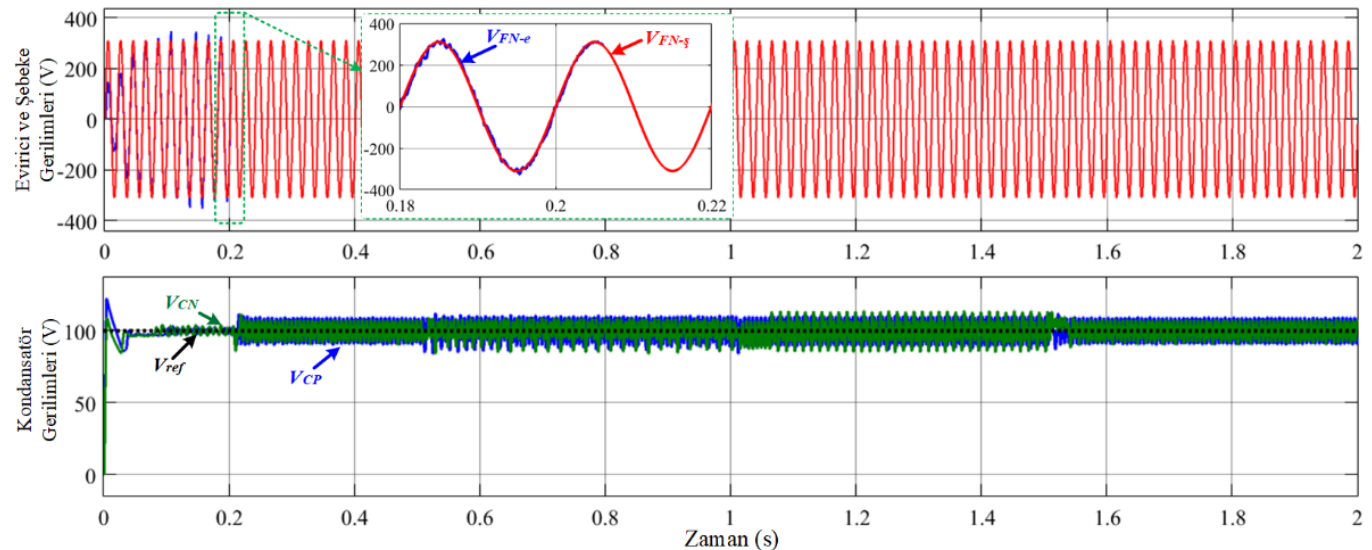

Şekil 9. Nötr noktasının kontrollü olduğu duruma ait evirici ve kondansatör gerilimleri
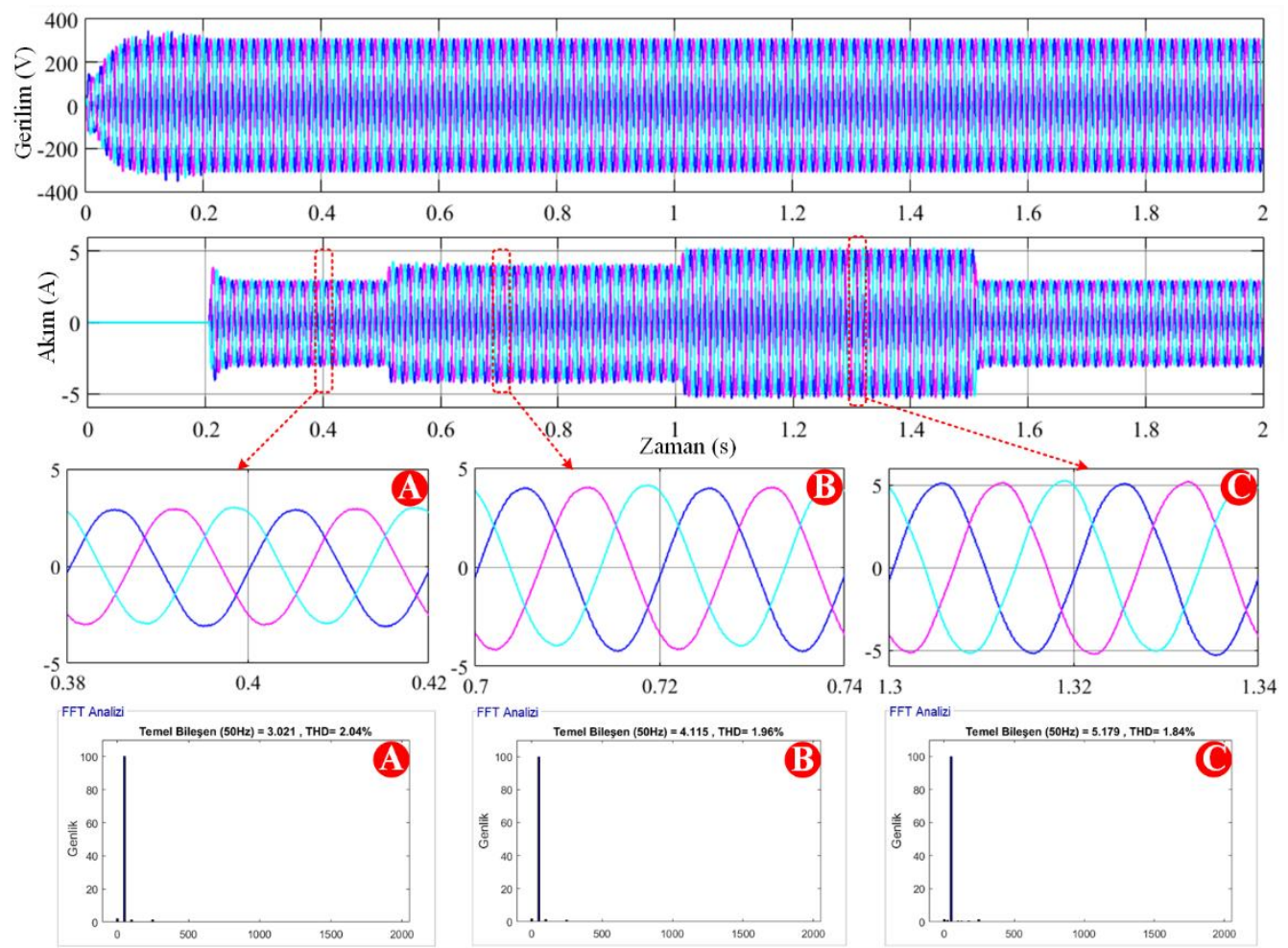

Şekil 10. Nötr noktasının kontrollü olduğu duruma ait gerilim, akım ve bozunum sonuçları 
Güç değişimleri esnasında kondansatör gerilimi sonuçları Şekil 9'da verilmiştir. Eviricinin şebeke etkileşimli çalışmaya başlamasının ardından, kondansatörden çekilen akımın artması salınımları da artırmaktadır. Fakat gerilimlerin ortalama değeri referansa (100V) eşittir.

Benzetim çalışmaları boyunca ölçülen akım ve gerilim sinyalleri Şekil 10 'da verilmiştir. $1.5 \mathrm{~kW}$ referans değer için verilen A sürecinde, akım sinyali üzerinde yüksek bir bozucu etkinin olmadığı grafikten görülmektedir. $\mathrm{Bu}$ süreçte toplam bozunum \%2.04'tür. Kontrolsüz çalışma durumuna göre toplam bozunum \%0.8 azalmıştır.

Referans değerin $2 \mathrm{~kW}$ 'a çıkarılması durumuna ait sonuçlar, B ile belirtilen detay grafiği ve bozunum analizinde verilmiştir. Akım sinyalinin oldukça ideale yakın ve bozunum değerinin \%1.96 olduğu analiz sonuçlarından görülmektedir. Kontrolsüz durumdaki sonuçlar ile karşılaştırıldığında bozunumların önemli oranda azaltıldı̆̆ı söylenebilir.

$\mathrm{C}$ detay grafiği ve bozunum analizi, evirici $2.5 \mathrm{~kW}$ referans değer ile çalışırken elde edilmiştir. Akım üzerindeki bozunumların \%1.84 gibi oldukça düşük değere sahip olduğu analiz sonucundan görülmektedir. Kontrolsüz durumdaki aynı sürece göre bozunumlar, önemli oranda azaltılarak standartlarda belirtilen limitin altına indirilmiştir.

Nötr noktası kontrollü ve kontrolsüz iken yapılan benzetim çalışmaları, gerilim dengesizliğinin bozunumları olumsuz etkilediğini ve bu durumun önerilen çevirici yapısı ile DA barada giderildiğini göstermiştir.

Kontrollü ve kontrolsüz durum için elde edilen sonuçlar IEEE 1547 standartlarına göre bileşen bazında ve toplam bozunum olarak ayrı ayrı incelenmiştir. Belirli bir bileşen aralığ için toplam bozunum $\left(T H D_{n \rightarrow m}\right)$ Denklem 6 kullanılarak hesaplanmıştır. Çalışma durumlarındaki bozunum sonuçlarının karşılaştırması Tablo 3 'te sunulmuştur. Tablodan görüldüğü üzere, 11'inci bileşenden küçük sinyallerin \%4'ü aşmamas1, 11 ile 17 bileşen arasında kalan sinyallerin ise \%2 değerinden düşük olması standartlarda belirtilen limitlerdir. $\mathrm{Bu}$ çalışmada elde edilen benzetim sonuçlarında 17'nci bileşenden sonra bozunum görülmediğinden incelemeler bu değere kadar yapılmıştır.

$$
T H D_{n \rightarrow m}=\frac{\sqrt{\sum_{n}^{m} i_{n}^{2}}}{i_{1}}
$$

Burada;

$n$ : İlk bozunum bileşeni

$m$ : Belirtilen aralık için son bozunum bileşeni

$i_{1}$ : Temel bileşen

Tablo 3. IEEE 1547 Standartlarına Göre Detaylı Bozunum Sonuçları

\begin{tabular}{|c|c|c|c|c|}
\hline & & $h<11(\%)$ & $11 \leq h<17(\%)$ & THD (\%) \\
\hline Lim & & $\% 4$ & $\% 2$ & $\% 5$ \\
\hline$:=$ & A & 2.84 & 0.33 & 2.86 \\
\hline 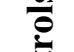 & B & 13.25 & 0.85 & 13.28 \\
\hline$\underline{\tilde{\theta}}$ & C & 10.28 & 0.82 & 10.31 \\
\hline & $\mathbf{A}$ & 2.04 & 0 & 2.04 \\
\hline $\bar{O}$ & B & 1.96 & 0 & 1.96 \\
\hline$\stackrel{0}{1}$ & C & 1.83 & 0.19 & 1.84 \\
\hline
\end{tabular}


Tablo 3'te verilen sonuçlardan görüldüğü üzere, gerilim dengesinin kontrolsüz olduğu benzetim sonuçlarındaki $B$ ve $C$ sürecinde bozunumlar belirtilen limitlerin üzerindedir. Kontrollü durum için elde edilen sonuçlardaki tüm süreçlerde bozunumlar limitlerin oldukça altındadır.

Önerilen model ile hedeflenen diğer bir durum da NKE modelinin çok girişli hale getirilmesi olarak belirtilmişti. Bu durumun incelenmesi için, giriş akımlarının ortalama değerleri $\left(I_{I}\right.$ ve $\left.I_{2}\right)$ ve giriş gerilimleri $\left(V_{i n 1}\right.$ ve $\left.V_{i n 2}\right)$ Şekil 11'de verilmiştir. Başlangıçta kondansatörlerin boş olması sebebiyle çekilen yüksek akımlar şekilde verilmemiştir. Ortalama akım değerleri, kondansatör gerilimlerinin kararlı duruma geçmesinden sonra çizdirilmiştir.
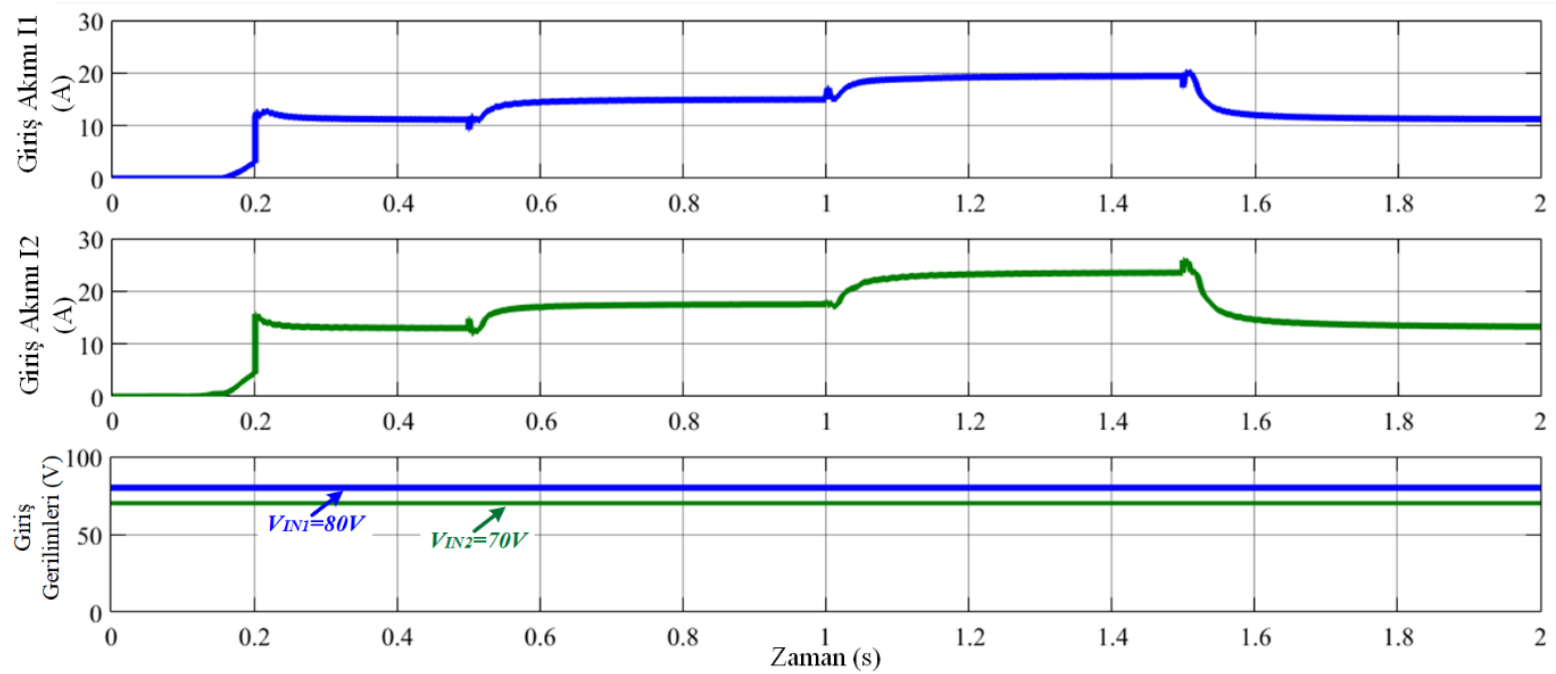

Şekil 11. Çevirici giriş akım ve gerilimleri

Şekil 11'den görüldüğü üzere, evirici - şebeke etkileşiminin $1.5 \mathrm{~kW}$ referans ile başlamasının ardından, her iki giriş kaynağından çekilen akımlar ani olarak artmıştır. Benzetim süresi boyunca giriş gerilimlerinin farklı olması sebebiyle kaynak akımları da birbirinden farklı değerdedir. Güç akışı için yapılan diğer basamak değişimlerinde de her iki kaynaktan güç akışının devam ettiği Şekil 11'de görülmektedir. Bu durumlar çeviricinin çok kaynaklı çalışabilirliği sağladığını doğrulamaktadır.

\section{SONUÇLAR (CONCLUSION)}

Bu çalışmada nötr kenetlemeli eviricilerin çok kaynaklı çalışabilmesi ve gerilim dengesizliğinin giderilmesi için iki giriş - iki çıkışlı bir DA-DA çevirici modeli oluşturulmuştur. Nötr kenetlemeli evirici, önerilen çevirici modeli üzerinden iki giriş kaynağına entegre edilmiştir. Giriş kaynaklarından şebekeye güç akışını kontrol eden denetleyici yapılarına ait detaylı incelemeler sunulmuştur.

Önerilen model ve kontrol işlemlerinin testi için benzetim çalışmaları yapılarak güç akışı, çok kaynaklı çalışabilirlik ve gerilim dengesizliği durumları incelenmiştir. İki giriş kaynağında üretilen enerjinin önerilen çevirici yapısı üzerinde birleştirildiği ve NKE aracılığıyla şebekeye güç akışının sağlandığı doğrulanmıştır. Bununla birlikte, gerilim dengesizliğinin kontrollü ve kontrolsüz olduğu durumlar için benzetim çalışmaları yapılmıştır. Nötr noktası kontrolsüz olarak gerçekleştirilen benzetim çalışmasında, güç akışının giriş kondansatörlerindeki gerilim eşitliğini bozduğu görülmüştür. Buna bağlı olarak, evirici çıkış akımı üzerindeki toplam bozunum \%13 gibi standartlarda kabul edilmeyen seviyelere yükselmiştir. Önerilen çevirici modeli ile gerilim dengesinin sağlandığı ve bozunumların \%2 gibi IEEE 1547 standartlarında belirtilen limitin oldukça altında değerlere düşürüldüğü yapılan benzetim çalışmaları ile doğrulanmıştır.

\section{TEŞEKKÜR (ACKNOWLEDGMENTS)}

Bu çalışma Gazi Üniversitesi Bilimsel Araştırma Projeleri Birimi (Proje No: $\quad$ 07/2017-08) tarafından desteklenmiştir. Katkılarından dolayı Gazi Üniversitesi Bilimsel Araştırma Projeleri Birimi'ne teşekkürlerimizi sunarız. 


\section{KAYNAKLAR (REFERENCES)}

[1] S. Özçıra, Aktif Güç Filtre Tipinin Kompanze Edilmesi Gereken Büyüklüğe Göre Belirlenmesi, Gazi Üniversitesi Fen Bilimleri Dergisi Part C: Tasarım ve Teknoloji, 6(3) (2018) 691-704.

[2] M. Schweizer, J. W. Kolar, Design and Implementation of a Highly Efficient Three-Level T-Type Converter for Low-Voltage Applications, IEEE Transactions on Power Electronics, $28: 2$ (2013) 899907.

[3] K. Komatsu, M. Yatsu, S. Miyashita, S. Okita, H. Nakazawa, S. Igarashi, Y. Takahashi, Y. Okuma, Y. Seki, T. Fujihira, New IGBT modules for advanced neutral-point-clamped 3-level power converters, International Power Electronics Conference - ECCE ASIA -, Sapporo, (2010) 523-527.

[4] P. Kakosimos, H. Abu-Rub, Predictive Control of a Grid-Tied Cascaded Full-Bridge NPC Inverter for Reducing High-Frequency Common-Mode Voltage Components, IEEE Transactions on Industrial Informatics, 14: 6 (2018) 2385-2394.

[5] M. Szarek, A. Penczek, R. Stala, S. Piróg, A. Mondzik, NPC three level inverter with dual DC bus for independent distributed generators. Neutral-point voltage balancing under the input power imbalance, 19th European Conference on Power Electronics and Applications (EPE'17 ECCE Europe), Warsaw, (2017) 1-10.

[6] I. Forrisi, J. P. Martin, B. Nahid-Mobarakeh, S. Pierfederici, PV-grid system in mismatch operating mode: Improvement through a new voltage balancing method in multilevel NPC inverters, IEEE 25th International Symposium on Industrial Electronics (ISIE), Santa Clara, CA, (2016) 1280-1285.

[7] Y. Liu, H. Abu-Rub, B. Ge, Front-End Isolated Quasi-Z-Source DC-DC Converter Modules in Series for High-Power Photovoltaic Systems-Part I: Configuration, Operation, and Evaluation, IEEE Transactions on Industrial Electronics, 64:1 (2017) 347-358.

[8] R. Faraji, H. Farzanehfard, Soft-Switched Nonisolated High Step-Up Three-Port DC-DC Converter for Hybrid Energy Systems, IEEE Transactions on Power Electronics, 33:12 (2018) 10101-10111.

[9] E. Irmak, N. Güler, Application of A Boost Based Multi-Input Single-Output DC/DC Converter, 6th International Conference on Renewable Energy Research and Applications (ICRERA), San Diego, USA, (2017) 955-961.

[10] Chung-Ming Young, Ting-Ruei Fan, Two-stage interleaved three-level DC/AC converter with neutral point voltage balancing, IEEE 3rd International Future Energy Electronics Conference and ECCE Asia (IFEEC), Kaohsiung, (2017) 1430-1434.

[11] P. Wang, L. Zhou, Y. Zhang, J. Li, M. Sumner, Input-Parallel Output-Series DC-DC Boost Converter With a Wide Input Voltage Range, For Fuel Cell Vehicles, IEEE Transactions on Vehicular Technology, 66: 9 (2017) 7771-7781.

[12] A. Ganjavi, H. Ghoreishy, A. A. Ahmad, A Novel Single-Input Dual-Output Three-Level DC-DC Converter, IEEE Transactions on Industrial Electronics, 65: 10 (2018) 8101-8111.

[13] N. Güler, E. Irmak, Design and Application of A Novel Single Input - Multi Output DC/DC Converter, IEEE International Conference on Renewable Energy Research and Applications (ICRERA), Birmingham, (2016) 1039-1045.

[14] B. Wang, L. Xian, V. R. K. Kanamarlapudi, K. J. Tseng, A. Ukil, H. B. Gooi, A Digital Method of Power-Sharing and Cross-Regulation Suppression for Single-Inductor Multiple-Input Multiple-Output DC-DC Converter, IEEE Transactions on Industrial Electronics, 64: 4 (2017) 2836-2847. 
[15] Y. Tong, Z. Shan, J. Jatskevich, A. Davoudi, A nonisolated multiple-input multiple-output DC-DC converter for DC distribution of future energy efficient homes, 40th Annual Conference of the IEEE Industrial Electronics Society, Dallas, TX, (2014) 4126-4132.

[16] P. Mohseni, S. H. Hosseini, M. Sabahi, T. Jalilzadeh, M. Maalandish, A New High Step-Up MultiInput Multi-Output DC-DC Converter, IEEE Transactions on Industrial Electronics, Basim aşamasında (2018).

[17] L. Zhang, K. Sun, M. Gu, D. Xu, Y. Gu, A Capacitor Voltage Balancing Control Method for FiveLevel Full-Bridge Grid-Tied Inverters Without Split-Capacitor Voltage Sampling, IEEE Journal of Emerging and Selected Topics in Power Electronics, 6: 4 (2018) 2042-2052.

[18] E. Irmak, N. Güler, Model predictive control of grid-tied three level neutral point clamped inverter integrated with a double layer multi-input single output DC/DC converter, IEEE 12th International Conference on Compatibility, Power Electronics and Power Engineering (CPE-POWERENG), Doha, (2018) 1-6.

[19] C. Zhang, C. Hu, G. Fang, H. Li, Z. Qian, An improved SVPWM strategy for three-level active NPC inverter, 12th IEEE Conference on Industrial Electronics and Applications (ICIEA), Siem Reap, (2017) 292-296.

[20] C. Hu, G. Holmes, W. Shen, X. Yu, Q. Wang, F. Luo, Neutral-point potential balancing control strategy of three-level active NPC inverter based on SHEPWM, IET Power Electronics, 10: 14 (2017) 1943-1950.

[21] F. Donoso, A. Mora, R. Cárdenas, A. Angulo, D. Sáez, M. Rivera, Finite-Set Model-Predictive Control Strategies for a 3L-NPC Inverter Operating With Fixed Switching Frequency, IEEE Transactions on Industrial Electronics, 65: 5 (2018) 3954-3965.

[22] Ş. Özdemir, Yenilenebilir Enerji Kaynaklari için Tek Aşamali MPPT Denetimli Çok Seviyeli Eviricinin Gerçekleştirilmesi, Doktora Tezi, Gazi Üniversitesi (2013).

[23] G. I. Orfanoudakis, S. M. Sharkh, M. A. Yuratich, Circuit for reducing devices voltage stress due to DC-link capacitor voltage ripple in a Neutral-Point-Clamped inverter, Proceedings of the 2011 14th European Conference on Power Electronics and Applications, Birmingham, (2011) 1-10.

[24] B. Ren, X. Sun, S. An, X. Cao, Q. Zhang, Analysis and design of an LCL filter for the three-level gridconnected inverter, Proceedings of The 7th International Power Electronics and Motion Control Conference, Harbin, (2012) 2023-2027. 